
About IJMA [last updated July, $\left.1^{\text {st }}, 2021\right]$

$\checkmark$ International Journal of Medical Arts is the Official Journal of the Damietta Faculty of Medicine, AlAzhar University, Egypt

$\checkmark$ It is an International, Open Access, Double-blind, Peer-reviewed Journal

$\checkmark$ Published four times a year

$\checkmark$ The First Issue was published in July 2019

$\checkmark$ Published under the following license: Creative Commons Attribution-ShareAlike 4.0 International Public License (CC BY-SA 4.0). It had updated from the Creative Commons license [CC BY] in volume 2, Issue 4, October 2020 About IJMA

$\checkmark$ The Egyptian Knowledge Bank hosts the web site of IJMA

$\checkmark$ The Egyptian Knowledge Bank supports IJMA

$\checkmark$ IJMA follows the regulations of the International Committee of Medical Journal Editors

$\checkmark$ IJMA is indexed in the "Directory of Open Access Journals" [15 January 2021].

$\checkmark$ IJMA is indexed in JGate [29-6-2021]

$\checkmark$ IJMA is a member of the International Society of Managing and Technical Editors

$\checkmark$ Listed in "Index Copernicus", "Publons", "Academic resource index [ResearchBib]", "Electronics journal library", "Eurasian Scientific Journal Index", and "Citefactor"

$\checkmark$ IJMA introduced to the search engine [BASE] through DOAJ
Click image to reach the page

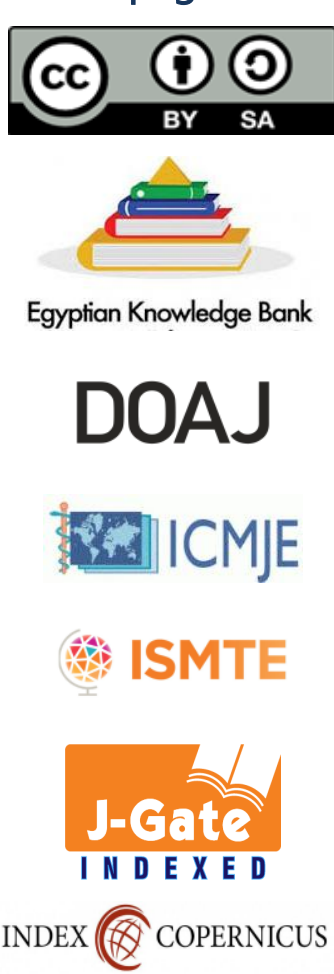

publons

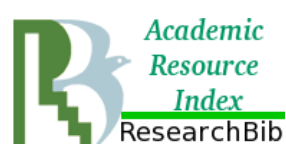

\section{EZ3 \\ .}

ESJII

CiteFactor

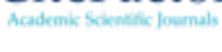

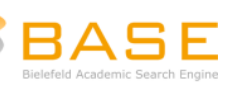




Available online at Journal Website
https://ijma.journals.ekb.eg/
Main subject [Neurology]

Original Article

\title{
Fatigue in A sample of Egyptian Multiple Sclerosis Patients: A Cross Sectional Study
}

\author{
Mohammad Ali Saeed Hassan
}

Department of Neurology, Faculty of Medicine, Al-Azhar University, Egypt.

Corresponding author: Mohammad Ali Saeed Hassan.

Email: m.elomairy@gmail.com

Submission date: May 16, 2021; Revision date: July 03, 2021; Acceptance date: July 10, 2021.

\section{ABSTRACT}

Background: Multiple sclerosis [MS] is an inflammatory demyelinating disease of the central nervous system, which is the secondmost common cause of physical handicap in young individuals. Fatigue is the most prevalent [50\%-90\%] symptom of MS interfering with everyday life with at least one mild symptom of fatigue even in the early stages of the disease [36.5\%] when clinical symptoms are still negligible.

The Aim of The Work: To evaluate the prevalence and relation of fatigue in MS patients with sleep disorders and other clinical factors in an attempt to understand the underlying mechanisms of this symptom which might be of help in easing its evaluation and optimizing patient care.

Patients and Methods: A cross-sectional study was performed on patients recruited from MS unit at Al-Azhar University Hospitals in Cairo. Fifty patients were investigated and submitted to clinical evaluation as well as fatigue severity assessment using fatigue severity scale and sleep scales: Epworth sleepiness scale for assessment of daytime sleepiness, Pittsburgh sleep scale for assessment of sleep quality, and polysomnography.

Results: Fatigue was present in $60 \%$ of MS patients. Decreased sleep efficiency, pain and progressive types were significantly higher among MS patients with fatigue. Male patients with fatigue were significantly more than those without fatigue. About $84 \%$ of patients with MS were complaining from sleep disorder symptoms, $72 \%$ had insomnia, pain and nocturia ranged from $54 \%$ $60 \%$ while leg spasm and narcolepsy were present in $30 \%$ and $20 \%$ respectively.

Conclusion: The present study emphasized the prevalence of fatigue in MS patients and its relation with sleep disorders and disease progression denoting wide variety of pathological mechanisms and the necessity of multimodal management.

Keywords: Sleep disorders; Polysomnography; Fatigue Scales; Sleep scales.

This is an open-access article registered under the Creative Commons, ShareAlike 4.0 International license [CC BY-SA 4.0] [https://creativecommons.org/licenses/by-sa/4.0/legalcode.

Citation: Hassan MAS. Fatigue in a sample of Egyptian multiple sclerosis patients: A cross section study. IJMA 2021; 3 [3] July-September: 16811688. [DOI: 10.21608/IJMA.2021.76416.1312].

${ }^{*}$ Main subject and any subcategories have been classified according to the research topic. 


\section{INTRODUCTION}

Multiple sclerosis [MS] is a central nervous system inflammatory demyelinating disease that is the second most common cause of physical disability in young patients [1]. Demyelination, synaptopathy, and neurodegeneration are the pathophysiological hallmarks ${ }^{[2]}$ of the disease. Based on studies using an animal model of MS, immune-mediated processes involving immune cells and soluble cytokines could also lead to excitotoxic changes and neurodegeneration, whereas an immune-mediated attack by blood-borne autoreactive T lymphocytes will determine the incidence of demyelination ${ }^{[3]}$.

Fatigue is the most common symptom [50-90\%] of MS that interferes with daily life, with at least one mild symptom of fatigue that will be present in the early stages of the disease [36.5\%] when clinical symptoms are still minimal [4]. In fact, the definition of fatigue remains vague. The MS council for clinical practice guidelines has defined it as "a subjective lack of physical or mental energy or both, that is perceived by the individual or caregiver to interfere with the usual and desired activities". Patients describe it as a difficult symptom that worsens during the day, as well as in hot and humid conditions [2]. MS fatigue is a multidimensional symptom with physical, cognitive, and psychosocial aspects, according to scientific bases. Furthermore, the construct can be separated into fatigability, which is objectively evaluated by motor/cognitive task output, and self-reported fatigue, which is measured by a self-administered questionnaire [5].

Since fatigue is a subjective experience, it can only be assessed directly by verbal reports, so it is mainly measured through questionnaires and clinical interviews [6]. In terms of primary factors, a number of studies have looked into the role of central and peripheral inflammatory processes in MS fatigue. The relationship between fatigue and the orexin- $A$ system ${ }^{[7]}$, the hypothalamic-pituitary-adrenal axis ${ }^{[8]}$, and some CSF markers ${ }^{[9,10]}$ was inconclusive.

Although the available evidence was restricted, serum proinflammatory cytokines [i.e., IL6, TNF, and IFN] appeared to be linked to MS fatigue [5]. Finally, a few data were available on the T-cell population [CD3+, CD4+ T lymphocytes] [11] or regulatory-T cells ${ }^{[12]}$ or peripheral markers of inflammation [CRP, ESR, and soluble ICAM1] [1315], and such studies failed to find a correlation between MS fatigue and these measures ${ }^{[5]}$.

As indicated by the common finding of exercise intolerance, some MS patients with fatigue may also have features of autonomic dysregulation, such as hypoadrenergic orthostatic response ${ }^{[16]}$.
Neuroimaging studies resulted in plenty of intriguing leads in the search for a connection between MS and fatigue. The majority of early studies that used traditional MRI measures of lesion burden or lesion position found no connection between fatigue ratings and the severity of the lesion [17]. Studies using more sophisticated imaging measures, on the other hand, have found links between fatigue and regional atrophy [18], as well as pathways attaching frontal white matter to the thalamus and basal ganglia [19]. Cortical thickness, disturbance of fronto-parietal white matter lesion burden, and tests of axonal injury using MR spectroscopy are among the other MRI findings linked to self-reported fatigue ${ }^{[20]}$.

Individuals with MS who performed a repetitive motor task had more cortical activity in the frontal and motor areas, while this activity was limited in those who performed a task involving continuous hand grip [21], according to functional MRI studies [22]. The declining performance in MS cases have been related to increased activation in the basal ganglia, frontal areas [superior, medial, middle, and inferior regions], parietal regions [precuneus and cuneus], thalamus, and occipital lobes [23]. Furthermore, the influence of environmental, genetic, and epigenetic MS risk factors on MS fatigue is significant. UV exposure, vitamin D consumption, smoking, dietary, and exercise behaviors, as well as body mass index, are all variables to consider [24].

Controlling some confounders that are common in MS and can affect MS fatigue is also important. Physical impairment [25], mental symptoms [26, 27], and sleep disturbances are among them [28]

\section{AIM OF THE WORK}

The aim of this study is to assess fatigue in MS patients and its relation to clinical as well as different contributing factors as pain and sleep disorders in an attempt to improve the understanding of this common symptom as a necessary step for proper management.

\section{SUBJECTS AND METHODS}

Study design: A cross-sectional study was carried out at the MS unit of Neurology Department at Al-Azhar University Hospitals [Al Hussein and Bab Al-sharia] during the period from October 2018 to December 2020.

Inclusion criteria: Fifty MS patients and twenty-five healthy volunteers were included in the current study. Those patients were further assorted based on modified McDonald's Criteria 2017 [29].

Exclusion criteria: 1- Patients with systemic disease 
that could affect sleep or cause fatigue as: hepatic failure, renal failure, chest diseases, etc. [30]. 2- Patients who received corticosteroid drugs in the previous 3 months [30]. 3- Patients with psychiatric disorders that could affect sleep or fatigue as depression or bipolar disorder, etc. ${ }^{[31]}$.

\section{All participants were subjected to:}

1- Full history taking, general and neurological examination. 2- Clinical severity assessment of MS patients using expanded disability status scale [EDSS] ${ }^{[31]}$. 3- Fatigue severity assessment using fatigue severity scale, in which a score of 5 or more was indicative of fatigue [range; 0-17] [5]. 4- Sleep scales: Epworth sleepiness scale [ESS] for the assessment of daytime sleepiness, where a score of more than 10 indicating excessive day time sleepiness [32], and Pittsburgh sleep scale [PSC] for the assessment of sleep quality, based on a zero to three scale, in which three reflects the negative extreme on the scale [33]. 5Polysomnography [PSG]: Full laboratory-based PSG and scoring followed the standards of American Academy of Sleep Medicine 2007 [34, 35].

Ethical approval: The ethical approval has been obtained from Al-Azhar Faculty of Medicine's local ethical committees in Cairo. Prior to enrollment in the trial, written informed consents of the participants were obtained. Using a unique code number for each patient, privacy and confidentiality was preserved throughout the study process.

Statistical analysis of data: The SPSS computer package version 25.0 [IBM SPSS Statistics for Windows, Version 25.0. Armonk, NY: IBM Corp., USA] was used. For quantitative data, the mean and standard deviation SD were utilized, while for qualitative variables, the frequency and percentage were employed. The Mann-Whitney test was used to analyze differences in means of quantitative nonparametric variables, whereas the Chi-square test or Fisher's Exact test was used to analyze variations in frequency of qualitative variables. The statistical methods were checked using a $p<0.05$ significance level.

\section{RESULTS}

The study comprised $50 \mathrm{MS}$ patients with a mean age of $28.4 \pm 8.0$ years, ranging from 18 to 45 years, 64 percent of whom were females, a mean illness duration of $5.2 \pm 2.6$ years, a mean age of disease onset of $26.6 \pm 6.4$ years, and a mean $\mathrm{BMl}$ of $23.9 \pm 3.2[\mathrm{~kg} / \mathrm{m} 2]$ ranging from 16 to 29 years [Figure 1].

The most common type of MS was SPMS [54\%] followed by RRMS [34\%] and PPMS [12\%], the mean expanded disability status scale [EDSS] was $3.8 \pm 1.6$, the mean mini mental state was $29.1 \pm 0.9$ and sensory symptoms were prevalent in $58 \%$ of patients. Half of the patients had motor symptoms; ataxia and optic neuritis were present in $12 \%$ for each and the least prevalent symptoms were trigeminal neuralgia and facial weakness, $4 \%$ for each [Table 1].

Both Pittsburgh and Epworth sleepiness scales were significantly higher $[P<0.001]$ among cases with $M S$ compared to controls [Figure 2].

PSG parameters among MS cases showed significant increases in stages $\mathrm{N} 1 \%$ and $\mathrm{N} 2 \%$, periodic $\operatorname{limb}$ movement, and respiratory disturbance index showed significant decrease in both sleep efficiency and REM percentage when compared with controls [Table 2].

Regarding sleep- related disorders, $84 \%$ of patients with MS complained from sleeping disorders symptoms, $72 \%$ had insomnia, pain and nocturia ranged from $54 \%-60 \%$ while leg spasms and narcolepsy were present in $30 \%$ and $20 \%$, respectively [Figure 3]. Thirty patients [60\%] had fatigue. Fatigue was significantly evident among males with MS. Decreased sleep efficiency, pain and progressive types of MS were significantly higher among patients with fatigue. Other variables did not show significant differences when stratified by fatigue [Table 3].

Table [1]: Clinical characteristics of multiple sclerosis among cases

\begin{tabular}{|c|c|c|}
\hline Variables & & Cases [n, \%] \\
\hline \multirow{3}{*}{ Type of MS } & RRMS & $17[34.0]$ \\
\hline & PPMS & $6[12.0]$ \\
\hline & SPMS & 27 [54.0] \\
\hline Expanded disability status scale & Mean \pm SD; Min - Max & $3.8 \pm 1.6 ; 1.5-6.5$ \\
\hline Mini mental state & Mean \pm SD; Min - Max & $29.1 \pm 0.9 ; 27-30$ \\
\hline Sensory symptoms & & 29 [58.0] \\
\hline Motor symptoms & & $25[50.0]$ \\
\hline Ataxia & & $6[12.0]$ \\
\hline Optic neuritis & & $6[12.0]$ \\
\hline Trigeminal neuralgia & & $2[4.0]$ \\
\hline Facial weakness & & $2[4.0]$ \\
\hline
\end{tabular}


Table [2]: Polysomnography parameters among the study samples

\begin{tabular}{|l|c|c|c|c|}
\hline \multicolumn{2}{|c|}{ Variables } & Cases & Control & P-value \\
\hline Sleep latency & Mean \pm SD; Min - Max & $23.4 \pm 18.8 ; 2-65$ & $19.7 \pm 4.4 ; 12-26$ & 0.362 \\
\hline Sleep efficiency \% & Mean \pm SD; Min - Max & $67.6 \pm 20.6 ; 19-95$ & $87.0 \pm 4.1 ; 81-95$ & $<0.001^{*}$ \\
\hline Stage N1\% & Mean \pm SD; Min - Max & $10.5 \pm 5.4 ; 2-22$ & $5.8 \pm 2.8 ; 1-10$ & $<0.001^{*}$ \\
\hline Stage N2\% & Mean \pm SD; Min - Max & $54.9 \pm 5.3 ; 40-64$ & $50.2 \pm 3.3 ; 45-56$ & $<0.001^{*}$ \\
\hline Stage N3\% & Mean \pm SD; Min - Max & $18.0 \pm 5.6 ; 5-30$ & $20.0 \pm 1.4 ; 18-22$ & 0.088 \\
\hline REMl latency [min] & Mean \pm SD; Min - Max & $61.5 \pm 40.8 ; 10-142$ & $64.4 \pm 5.4 ; 51-73$ & 0.726 \\
\hline REM\% & Mean \pm SD; Min - Max & $17.3 \pm 5.5 ; 5-33$ & $23.6 \pm 3.4 ; 19-30$ & $<0.001^{*}$ \\
\hline Periodic limb movement & Mean \pm SD; Min - Max & $4.8 \pm 5.0 ; 0-18$ & $1.4 \pm 1.0 ; 0.5-5$ & $0.001^{*}$ \\
\hline Respiratory disturbance index & Mean \pm SD; Min - Max & $7.1 \pm 8.1 ; 0-31$ & $0.4 \pm 0.3 ; 0-0.9$ & $<0.001^{*}$ \\
\hline
\end{tabular}

Values present as mean \pm SD were analyzed by Mann-Whitney $U$ test. * * Significant.

Table [3]: Relation of fatigue with different study variables among cases with multiple sclerosis

\begin{tabular}{|c|c|c|c|c|}
\hline \multicolumn{2}{|c|}{ Variables } & Fatigue [n=30] & No fatigue $[n=20]$ & P-value \\
\hline \multicolumn{2}{|l|}{ Age [years] } & $28.0 \pm 8.4$ & $29.0 \pm 7.6$ & 0.481 \\
\hline \multirow{2}{*}{ Sex $[n, \%]$} & Male & $15[50.0]$ & $3[15.0]$ & \multirow{2}{*}{$0.016^{*}$} \\
\hline & Female & $15[50.0]$ & $17[85.0]$ & \\
\hline \multicolumn{2}{|l|}{ BMI [kg/m2] } & $23.5 \pm 3.2$ & $24.4 \pm 3.2$ & 0.467 \\
\hline \multicolumn{2}{|c|}{ Mini mental state } & $29.0 \pm 1.0$ & $29.3 \pm 0.8$ & 0.265 \\
\hline \multicolumn{2}{|c|}{ Duration of illness [years] } & $5.5 \pm 2.4$ & $4.9 \pm 3.0$ & 0.196 \\
\hline \multicolumn{2}{|c|}{ Age of onset [years] } & $26.6 \pm 6.9$ & $26.6 \pm 5.6$ & 0.897 \\
\hline \multicolumn{2}{|c|}{ Pittsburgh scale } & $9.1 \pm 4.7$ & $11.6 \pm 5.0$ & 0.141 \\
\hline \multicolumn{2}{|c|}{ Epworth sleepiness scale } & $9.7 \pm 6.7$ & $8.9 \pm 6.8$ & 0.571 \\
\hline \multicolumn{2}{|l|}{ Sleep latency } & $19.7 \pm 15.4$ & $28.9 \pm 22.3$ & 0.117 \\
\hline \multicolumn{2}{|c|}{ Sleep efficiency $\%$} & $75.7 \pm 12.0$ & $55.3 \pm 24.8$ & $0.002^{*}$ \\
\hline \multicolumn{2}{|c|}{ Stage N1\% } & $9.7 \pm 5.1$ & $11.8 \pm 5.8$ & 0.261 \\
\hline \multicolumn{2}{|l|}{ Stage N2\% } & $54.5 \pm 5.1$ & $55.6 \pm 5.8$ & 0.374 \\
\hline \multicolumn{2}{|l|}{ Stage N3\% } & $17.8 \pm 5.2$ & $18.4 \pm 6.2$ & 0.850 \\
\hline \multicolumn{2}{|c|}{ REMl latency [min] } & $55.5 \pm 40.0$ & $70.5 \pm 41.4$ & 0.168 \\
\hline \multicolumn{2}{|l|}{ REM $\%$} & $18.3 \pm 5.8$ & $15.7 \pm 4.7$ & 0.127 \\
\hline \multicolumn{2}{|c|}{ Periodic limb movement } & $4.5 \pm 5.8$ & $5.3 \pm 3.7$ & 0.571 \\
\hline \multicolumn{2}{|c|}{ Respiratory disturbance index } & $8.2 \pm 9.7$ & $5.5 \pm 4.7$ & 0.937 \\
\hline \multicolumn{2}{|c|}{ Expanded disability status scale } & $3.7 \pm 1.6$ & $3.9 \pm 1.5$ & 0.617 \\
\hline \multicolumn{2}{|c|}{ Insomnia [positive] } & $21[70.0]$ & $15[75.0]$ & 0.758 \\
\hline \multicolumn{2}{|c|}{ Sleep disorder symptoms } & $24[80.0]$ & 18 [90.0] & 0.450 \\
\hline \multicolumn{2}{|l|}{ Pain } & 22 [73.3] & $5[25.0]$ & $0.001^{*}$ \\
\hline \multicolumn{2}{|l|}{ Leg spasm } & 10 [33.3] & $5[25.0]$ & 0.754 \\
\hline \multicolumn{2}{|l|}{ Nocturia } & 19 [63.3] & $11[55.0]$ & 0.572 \\
\hline \multicolumn{2}{|c|}{ Hypersomnolence } & 16 [53.3] & $5[25.0]$ & 0.079 \\
\hline \multicolumn{2}{|l|}{ Narcolepsy } & $6[20.0]$ & $4[20.0]$ & 1.000 \\
\hline \multirow{3}{*}{ Types of MS } & RRMS & $7[23.3]$ & $10[50.0]$ & \multirow{3}{*}{$0.037^{*}$} \\
\hline & PPMS & $6[20.0]$ & $0[0.0]$ & \\
\hline & SPMS & $17[56.7]$ & $10[50.0]$ & \\
\hline Sensory symp & & $20[66.7]$ & $9[45.0]$ & 0.154 \\
\hline Motor sympto & & 13 [43.3] & $12[60.0]$ & 0.387 \\
\hline Ataxia & & $5[16.7]$ & $1[5.0]$ & 0.381 \\
\hline Optic neuritis & & $3[10.0]$ & $3[15.0]$ & 0.672 \\
\hline Trigeminal ne & & $1[3.3]$ & $1[5.0]$ & 1.000 \\
\hline Facial weakne & & $1[3.3]$ & $1[5.0]$ & 1.000 \\
\hline
\end{tabular}

Values present as number \& \% were analyzed by Fisher's Exact or Chi-square tests. Values present as mean \pm SD were analyzed by Mann-Whitney U test. *: Significant. 


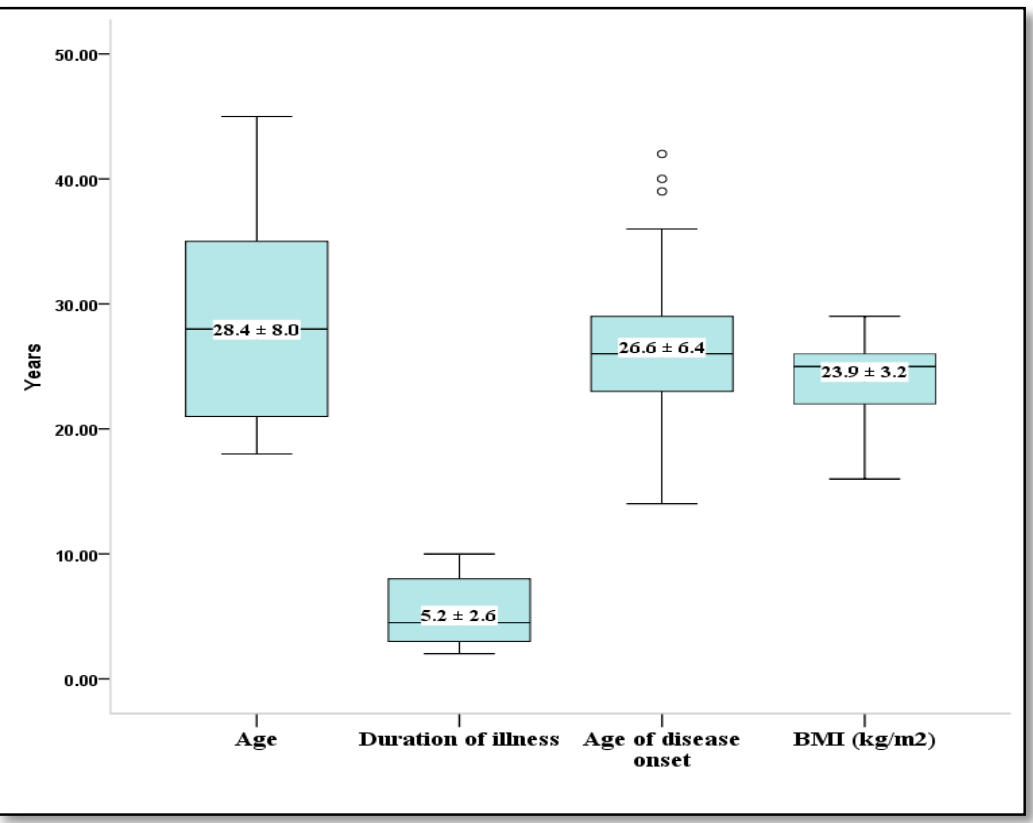

Figure [1]: Demographic characteristics of multiple sclerosis among cases.

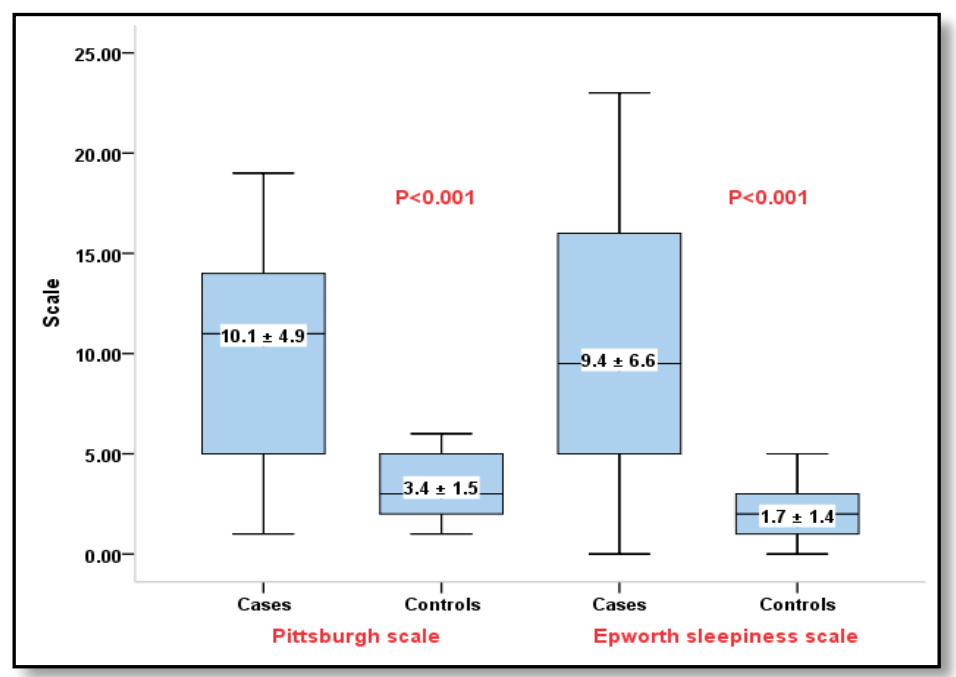

Figure [2]: Sleep related scales among the study samples.

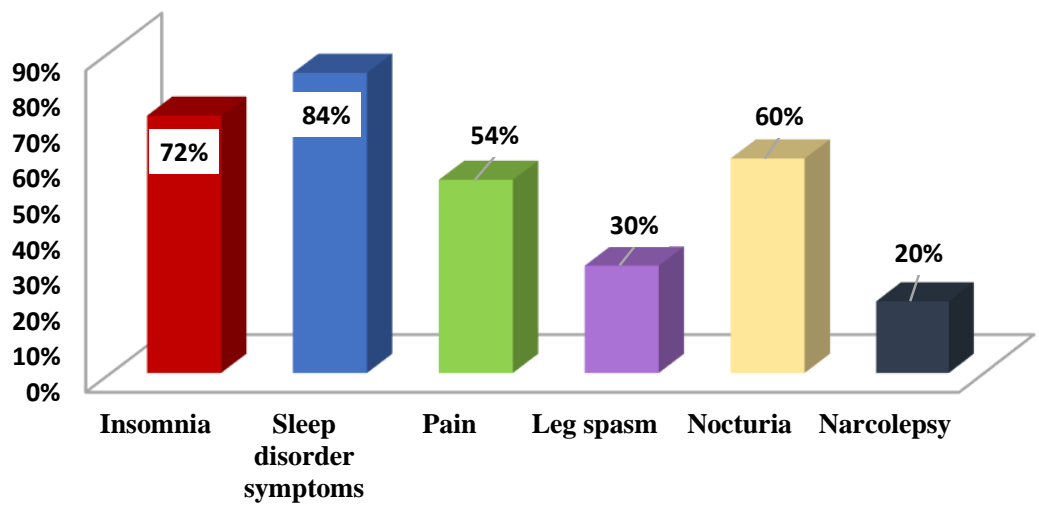

Figure [3]: Sleep-related disorders among cases with multiple sclerosis 


\section{DISCUSSION}

Individuals with MS can clearly differentiate their fatigue from feelings of weakness or emotional feelings of depression or listlessness [36], an observation stated in this study by the non-significant statistical difference between patients with and without fatigue regarding sleep quality and daytime sleepiness screened for by Pittsburgh and Epworth sleepiness scales respectively. The most prevalent symptom of MS is subjective fatigue [reported by more than 80 percent of patients in some studies [37], but only 60 percent in this study]. This could be due to variances in clinical features and other factors that contribute to fatigue, as well as the scales employed in different research. Fatigue occurs across all clinical subtypes of multiple sclerosis [MS] [38-40]. Patients with secondary progressive disease, on the other hand, may be at the greatest risk. Relapses, the accumulation of impairment and, in particular, the loss of ambulation; all raise the likelihood of fatigue ${ }^{[40,41]}$. Fatigue has been connected to the severity of disease and the overall severity of neurological impairment, but not to the duration of the condition [40]. This supports our findings as we did not find a significant difference between fatigued and non-fatigued patients regarding the duration of illness. Another contradiction was observed with clinical severity measured by EDSS which can be explained by the less severe cases in this study and the minority of patients with high EDSS scores.

The results of this study are matching with the mentioned studies regarding disease progression. In some research, cognitive impairment has been shown to be a risk factor for fatigue in MS [42, 43]; however there was no statistically significant difference between patients with and without fatigue in this study regarding cognition, which was assessed using the Mini Mental State Examination. This can be explained by the differences in fatigue definitions and assessments, as this study only employed the fatigue severity scale, which is primarily concerned with physical rather than cognitive domains. Although this conclusion has not been consistent ${ }^{[42,43]}$, age does not appear to be highly connected to fatigue in our study. Gender variations do not appear to be significant in fatigue frequency ${ }^{[42,43]}$ while, in our study, fatigue was significantly higher among males which may be explained by the more severe and progressive nature of MS in males than in females. Fatigue has a significant impact on people with MS, as it can affect all aspects of daily functioning and significantly reduce quality of life $[38,44,45]$. Studies have connected weariness to early retirement and unemployment ${ }^{42,46,47]}$. Furthermore, there appears to be a relation between fatigue and sleep disturbances in MS in this study as well as another study [48], since sleep disturbances and disorders are widespread in
MS patients [49]. Consistent with our findings, insomnia, sleep apnea, nocturia, periodic leg movements of sleep, and restless legs syndrome were all found to be more common in people with MS compared to healthy controls ${ }^{[49]}$. MS patients with severe fatigue were shown in some studies to have more than twice as many sleep disorders as those with little or no fatigue [50]. In this study, sleep respiratory disturbance was not significantly linked to fatigue which was the strongest factor in other studies ${ }^{[49,51]}$, differing, to some extent, with the present study. Overall, the link between sleep disorders and fatigue was not very significant which may be explained by the difference in other clinical factors, severity of the condition as well as the only focused physical domain of fatigue in this study. Fatigue is linked to pain in MS, according to this study as well as other studies. Muscle spasms and neuralgias are common causes of pain in MS patients. Pain can enhance tiredness and contribute to deconditioning, which can increase functional deficits ${ }^{[39]}$.

Study limitations: First: Most cases were not very severe, so the relation of study variables with disease severity may not be totally confirmed. Second: The distribution of clinical types of MS was not as that of the common types in general population [generally RRMS is the most common]. Third: Only physical domain has been assessed in this study, while other fatigue domains have not been subjected to assessment. Fourth: The effect of different drugs of disease-modifying therapy used by the participant patients may affect fatigue either positively or negatively.

Conclusions: Fatigue is a common symptom in MS, which may be underestimated. It is also related to several factors and has numerous economic and psychosocial hazards, so should it be carefully searched for and properly studied for better management.

Acknowledgement: I am extremely indebted to all members of Neurology Department, especially MS unit members of Al-Azhar University hospitals in Cairo, as well as all participants in the study for great help and cooperation.

Financial and Non-financial Relationships and Activities of Interest: None to be declared.

\section{REFERENCES}

1. Dendrou CA, Fugger L, Friese MA. Immunopathology of multiple sclerosis. Nat Rev Immunol. 2015 Sep 15;15[9]:54558. [DOI: 10.1038/nri3871.

2. Bertoli M, Tecchio F. Fatigue in multiple sclerosis: Does the functional or structural damage prevail? Mult Scler. 2020 Dec;26[14]:1809-1815. [DOI: 10.1177/1352458520912175. 
3. Centonze D, Muzio L, Rossi S, Furlan R, Bernardi G, Martino $G$. The link between inflammation, synaptic transmission and neurodegeneration in multiple sclerosis. Cell Death Differ. 2010 Jul;17[7]:1083-91. [DOI: 10.1038/cdd.2009.179].

4. von Bismarck O, Dankowski T, Ambrosius B, Hessler N, Antony G, Ziegler A, et al. Treatment choices and neuropsychological symptoms of a large cohort of early MS. Neurol Neuroimmunol Neuroinflamm. 2018 Mar 1; 5[3]:e446. [DOI: 10.1212/NXI.0000000000000446].

5. Chalah MA, Ayache SS. Is there a link between inflammation and fatigue in multiple sclerosis? J Inflamm Res. 2018 Jun 7; 11:253-264. [DOI: 10.2147/JIR.S167199].

6. Sander C, Voelter HU, Schlake HP, Eling P, Hildebrandt $H$. Assessment of fatigue in multiple sclerosis. Neurol Int Open. 2017 Apr; 1[02]:E79-85. [DOI: 10.1055/s-0043-104752].

7. Kos D, Kerckhofs E, Carrea I, Verza R, Ramos M, Jansa J. Evaluation of the Modified Fatigue Impact Scale in four different European countries. Mult Scler. 2005 Feb;11[1]:7680. [DOI: 10.1191/1352458505ms1117oa].

8. Akcali A, Zengin F, Aksoy SN, Zengin O. Fatigue in Multiple Sclerosis: Is it related to cytokines and hypothalamic-pituitaryadrenal axis? Mult Scler Relat Disord. 2017 Jul; 15:37-41. [DOI: 10.1016/j.msard.2017.03.004].

9. Biberacher V, Schmidt P, Selter RC, Pernpeinter V, Kowarik MC, Knier B, et al. Fatigue in multiple sclerosis: Associations with clinical, MRI and CSF parameters. Mult Scler. $2018 \mathrm{Jul}$; 24 [8]:1115-1125. [DOI: 10.1177/1352458517712078].

10. Brenner $P$, Granqvist M, Königsson J, Al Nimer F, Piehl F, Jokinen J. Depression and fatigue in multiple sclerosis: Relation to exposure to violence and cerebrospinal fluid immunomarkers. Psychoneuroendocrinology. 2018 Mar; 89: 53-58. [DOI: 10.1016/j.psyneuen.2018.01.002].

11. Pokryszko-Dragan A, Frydecka I, Kosmaczewska A, Ciszak L, Bilińska M, Gruszka E, Podemski R, Frydecka D. Stimulated peripheral production of interferon-gamma is related to fatigue and depression in multiple sclerosis. Clin Neurol Neurosurg. 2012 Oct; 114 [8]:1153-8. [DOI: 10.1016/ j.clineuro. 2012.02. 048].

12. Yaldizli O, Kumar M, Vago S, Kreuzfelder E, Limmroth $V$, Putzki N. Fatigue is not associated with impaired function of regulatory $T$ cells in untreated patients with multiple sclerosis. Eur Neurol. 2009;62[6]:321-6. [DOI: 10.1159/000236375].

13. Flachenecker P, Bihler I, Weber F, Gottschalk M, Toyka KV, Rieckmann P. Cytokine mRNA expression in patients with multiple sclerosis and fatigue. Mult Scler. 2004 Apr;10[2]:1659. [DOI: 10.1191/1352458504ms9910a].

14. Giovannoni G, Thompson AJ, Miller DH, Thompson EJ. Fatigue is not associated with raised inflammatory markers in multiple sclerosis. Neurology. 2001 Aug 28;57[4]:676-81. [DOI: 10.1212/wnl.57.4.676].

15. Adamczyk-Sowa M, Sowa P, Adamczyk J, Niedziela N, Misiolek H, Owczarek M, Zwirska-Korczala K. Effect of melatonin supplementation on plasma lipid hydroperoxides, homocysteine concentration and chronic fatigue syndrome in multiple sclerosis patients treated with interferons-beta and mitoxantrone. J Physiol Pharmacol. 2016 Apr;67[2]:235-42. [PMID: 27226183]

16. Foglio K, Clini E, Facchetti D, Vitacca M, Marangoni S, Bonomelli M, Ambrosino N. Respiratory muscle function and exercise capacity in multiple sclerosis. Eur Respir J. 1994 Jan;7[1]:23-8. [DOI: 10.1183/09031936.94.07010023].

17. Arm J, Ribbons K, Lechner-Scott J, Ramadan S. Evaluation of MS related central fatigue using MR neuroimaging methods: Scoping review. J Neurol Sci. 2019 May 15; 400:52-71. [DOI: 10.1016/j.jns.2019.03.007].

18. Andreasen AK, Jakobsen J, Soerensen L, Andersen H, Petersen T, Bjarkam CR, Ahdidan J. Regional brain atrophy in primary fatigued patients with multiple sclerosis. Neuroimage. 2010; 50 [2]: 608 - 15. [DOI: 10.1016/j.neuroimage. 2009.12. 118].

19. Calabrese M, Rinaldi F, Grossi P, Mattisi I, Bernardi V, Favaretto A, Perini P, Gallo P. Basal ganglia and frontal/ parietal cortical atrophy is associated with fatigue in relapsingremitting multiple sclerosis. Mult Scler. 2010 Oct; 16[10]:12208. [DOI: $10.1177 / 1352458510376405]$.

20. Pellicano C, Gallo A, Li X, Ikonomidou VN, Evangelou IE, Ohayon JM, et al. Relationship of cortical atrophy to fatigue in patients with multiple sclerosis. Arch Neurol. 2010 Apr; 67 [4]: 447-53. [DOI: 10.1001/archneurol.2010.48].

21. Mordillo-Mateos L, Soto-Leon V, Torres-Pareja M, PeinadoPalomino D, Mendoza-Laiz N, Alonso-Bonilla C, et al. Fatigue in Multiple Sclerosis: General and Perceived Fatigue Does Not Depend on Corticospinal Tract Dysfunction. Front Neurol. 2019 Apr 9; 10:339. [DOI: 10.3389/fneur.2019.00339].

22. White $A T$, Lee JN, Light AR, Light KC. Brain activation in multiple sclerosis: a BOLD fMRI study of the effects of fatiguing hand exercise. Mult Scler. 2009 May;15[5]:580-6. [DOI: $10.1177 / 1352458508100034]$.

23. Jaeger $S$, Paul F, Scheel M, Brandt A, Heine J, Pach D, Witt $\mathrm{CM}$, Bellmann-Strobl J, Finke C. Multiple sclerosis-related fatigue: Altered resting-state functional connectivity of the ventral striatum and dorsolateral prefrontal cortex. Mult Scler. 2019 Apr;25[4]:554-564. [DOI: 10.1177/1352458518758911].

24. Segal BM, Cohen JA, Antel J. Americas Committee for Treatment and Research in Multiple Sclerosis Forum 2017: Environmental factors, genetics, and epigenetics in MS susceptibility and clinical course. Mult Scler. 2018 Jan;24[1]:45. [DOI: $10.1177 / 1352458517737397]$.

25. Ayache SS, Chalah MA. Fatigue in multiple sclerosis - Insights into evaluation and management. Neurophysiol Clin. 2017 Apr;47[2]:139-171. [DOI: 10.1016/j.neucli.2017.02.004].

26. Chalah MA, Ayache SS. Psychiatric event in multiple sclerosis: could it be the tip of the iceberg? Braz J Psychiatry. 2017; 39[4]:365-368. [DOI: 10.1590/1516-4446-2016-2105].

27. Chalah MA, Ayache SS. Alexithymia in multiple sclerosis: A systematic review of literature. Neuropsychologia. 2017 Sep; 
104:31-47. [DOI: 10.1016/j.neuropsychologia.2017.07.034].

28. Hughes AJ, Dunn KM, Chaffee T. Sleep Disturbance and Cognitive Dysfunction in Multiple Sclerosis: a Systematic Review. Curr Neurol Neurosci Rep. 2018 Jan 29;18[1]:2. [DOI: 10.1007/s11910-018-0809-7].

29. Thompson AJ, Banwell BL, Barkhof F, Carroll WM, Coetzee T, Comi G, et al. Diagnosis of multiple sclerosis: 2017 revisions of the McDonald criteria. Lancet Neurol. 2018 Feb;17[2]:162173. [DOI: 10.1016/S1474-4422[17]30470-2].

30. Čarnická Z, Kollár B, Šiarnik P, Krížová L, Klobučníková K, Turčáni P. Sleep disorders in patients with multiple sclerosis. J Clin Sleep Med. 2015 Apr 15;11[5]:553-7. [DOI: 10.5664/ jcsm.4702].

31. Braley TJ, Chervin RD, Segal BM. Fatigue, tiredness, lack of energy, and sleepiness in multiple sclerosis patients referred for clinical polysomnography. Mult Scler Int. 2012; 2012: 673936. [DOI: 10.1155/2012/673936].

32. Johns MW. A new method for measuring daytime sleepiness: the Epworth sleepiness scale. Sleep. 1991 Dec;14[6]:540-5. [DOI: 10.1093/sleep/14.6.540].

33. Mollayeva T, Thurairajah P, Burton K, Mollayeva S, Shapiro $\mathrm{CM}$, Colantonio A. The Pittsburgh sleep quality index as a screening tool for sleep dysfunction in clinical and non-clinical samples: A systematic review and meta-analysis. Sleep Med Rev. 2016 Feb; 25:52-73. [DOI: 10.1016/j.smrv.2015.01.009].

34. Iber C, American Academy of Sleep Medicine. The AASM Manual for the Scoring of Sleep and Associated Events: Rules, Terminology and Technical Specifications, American Academy of Sleep Medicine, Westchester, III, USA, 2007.

35. Veauthier C, Paul F. Sleep disorders in multiple sclerosis and their relationship to fatigue. Sleep Med. 2014 Jan;15[1]:5-14. [DOI: 10.1016/j.sleep.2013.08.791]

36. Wessely S, Hotopf M, Sharpe D. Chronic fatigue and its syndromes. Oxford University Press; 1998.

37. Minden SL, Frankel D, Hadden L, Perloffp J, Srinath KP, Hoaglin DC. The Sonya Slifka Longitudinal Multiple Sclerosis Study: methods and sample characteristics. Mult Scler. 2006 Feb;12[1]:24-38. [DOI: 10.1191/135248506ms1262oa].

38. Amato MP, Ponziani G, Rossi F, Liedl CL, Stefanile C, Rossi L. Quality of life in multiple sclerosis: the impact of depression, fatigue and disability. Mult Scler. 2001 Oct;7[5]:340-4. [DOI: 10.1177/135245850100700511].

39. Patrick E, Christodoulou C, Krupp LB; New York State MS Consortium. Longitudinal correlates of fatigue in multiple sclerosis. Mult Scler. 2009 Feb;15[2]:258-61. [DOI: 10.1177/ 1352458508097466].

40. Mills RJ, Young CA. The relationship between fatigue and other clinical features of multiple sclerosis. Mult Scler. 2011 May;17[5]:604-12. [DOI: 10.1177/1352458510392262].

41. Flachenecker $P$, Meissner $H$. Fatigue in multiple sclerosis presenting as acute relapse: subjective and objective assessment. Mult Scler. 2008 Mar;14[2]:274-7. [DOI:
10.1177/1352458507082480].

42. Hadjimichael O, Vollmer T, Oleen-Burkey M; North American Research Committee on Multiple Sclerosis. Fatigue characteristics in multiple sclerosis: the North American Research Committee on Multiple Sclerosis [NARCOMS] survey. Health Qual Life Outcomes. 2008 Nov 14; 6:100. [DOI: 10.1186/1477-7525-6-100].

43. Lerdal A, Celius EG, Moum T. Fatigue and its association with sociodemographic variables among multiple sclerosis patients. Mult Scler. 2003 Oct;9[5]:509-14. [DOI: 10.1191/ 1352458503ms9430a].

44. Flachenecker $P$, Kümpfel $T$, Kallmann B, Gottschalk $M$, Grauer O, Rieckmann P, Trenkwalder C, Toyka KV. Fatigue in multiple sclerosis: a comparison of different rating scales and correlation to clinical parameters. Mult Scler. 2002 Dec;8[6]:523-6. [DOI: 10.1191/1352458502ms839oa].

45. Bakshi R, Shaikh ZA, Miletich RS, Czarnecki D, Dmochowski $\mathrm{J}$, Henschel $\mathrm{K}$, et al. Fatigue in multiple sclerosis and its relationship to depression and neurologic disability. Mult Scler. 2000 Jun; 6[3]:181-5. [DOI: 10.1177/135245850000600308].

46. Smith MM, Arnett PA. Factors related to employment status changes in individuals with multiple sclerosis. Mult Scler. 2005 Oct;11[5]:602-9. [DOI: 10.1191/1352458505ms1204oa].

47. Julian LJ, Vella L, Vollmer T, Hadjimichael O, Mohr DC. Employment in multiple sclerosis. Exiting and re-entering the work force. J Neurol. 2008; 255[9]: 1354-60. [DOI: 10.1007/ s00415-008-0910-y].

48. Veauthier C, Radbruch H, Gaede G, Pfueller CF, Dörr J, Bellmann-Strobl J, et al. Fatigue in multiple sclerosis is closely related to sleep disorders: a polysomnographic crosssectional study. Mult Scler. 2011 May;17[5]:613-22. [DOI: 10.1177/1352458510393772].

49. Côté I, Trojan DA, Kaminska M, Cardoso M, Benedetti A, Weiss $D$, et al. Impact of sleep disorder treatment on fatigue in multiple sclerosis. Mult Scler. 2013 Apr;19[4]:480-9. [DOI: 10.1177/1352458512455958].

50. Veauthier C, Radbruch H, Gade G, Pfuller C, Dorr J, Bellmann-Strobel $\mathrm{J}$, et al. Polysomnographic investigation of frequency of sleep disorders in consecutive unselected fatigued and non-fatigued multiple sclerosis patients. Neurology. 2010; 74[9]:A99.

51. Kaminska M, Kimoff RJ, Benedetti A, Robinson A, Bar-Or A, Lapierre Y, Schwartzman K, Trojan DA. Obstructive sleep apnea is associated with fatigue in multiple sclerosis. Mult Scler. 2012; 18[8]:1159-69. [DOI: 10.1177/13524585 11432328] 

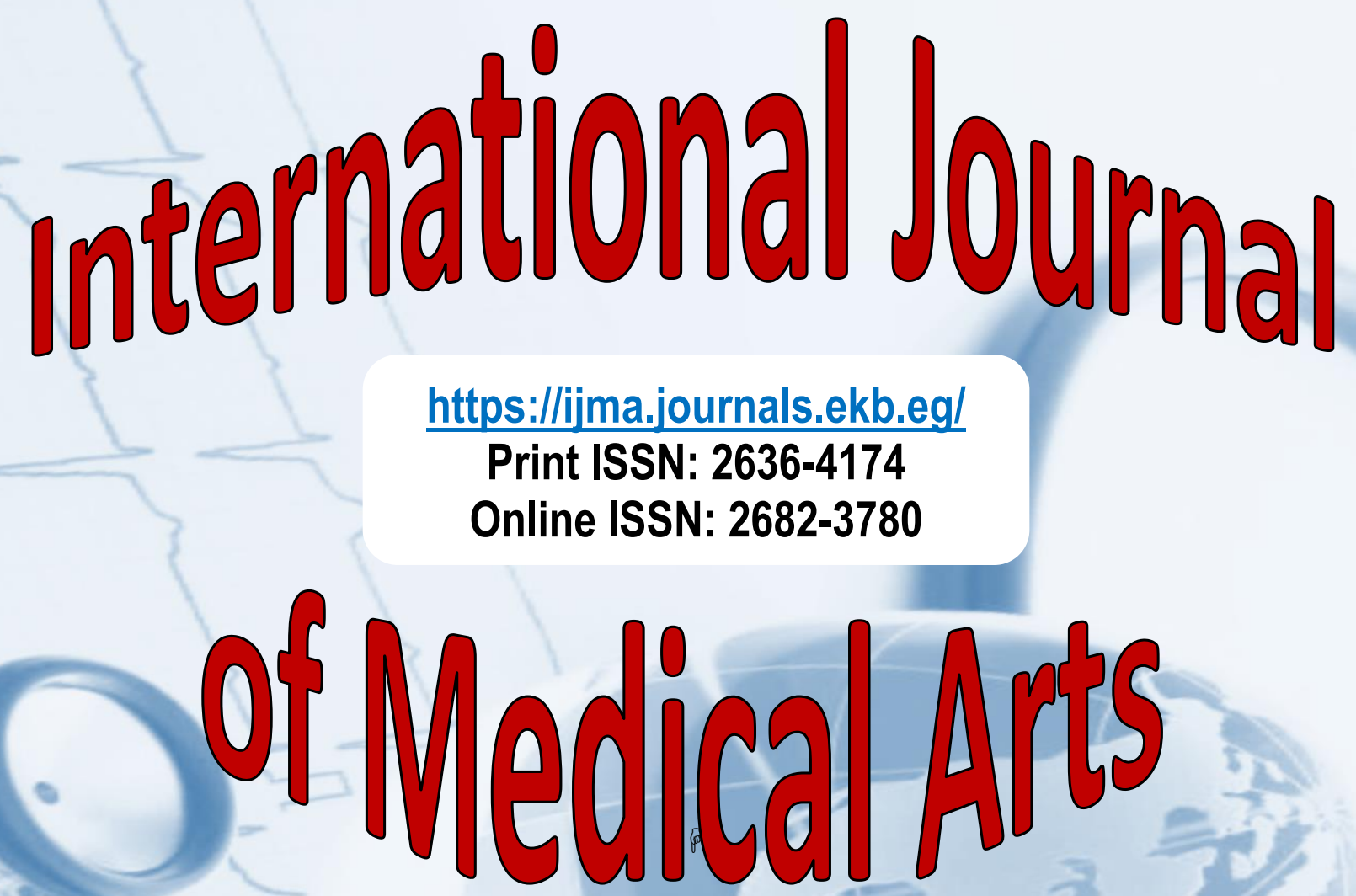